University of Nebraska - Lincoln

DigitalCommons@University of Nebraska - Lincoln

Faculty Publications, Department of Psychology

Psychology, Department of

August 2006

\title{
Elevated Positive Mood: A Mixed Blessing for Abstinence
}

\author{
Neal Doran \\ University of Illinois at Chicago \\ Bonnie Spring \\ University of Illinois at Chicago and Hines VA Hospital \\ Belinda Borrelli \\ Brown Medical School and The Miriam Hospital \\ Dennis E. McChargue \\ University of Nebraska-Lincoln, dmcchargue2@unl.edu \\ Brian Hitsman \\ Brown Medical School and The Miriam Hospital \\ See next page for additional authors
}

Follow this and additional works at: https://digitalcommons.unl.edu/psychfacpub

Part of the Psychiatry and Psychology Commons

Doran, Neal; Spring, Bonnie; Borrelli, Belinda; McChargue, Dennis E.; Hitsman, Brian; Niaura, Raymond; and Hedecker, Donald, "Elevated Positive Mood: A Mixed Blessing for Abstinence" (2006). Faculty

Publications, Department of Psychology. 279.

https://digitalcommons.unl.edu/psychfacpub/279

This Article is brought to you for free and open access by the Psychology, Department of at DigitalCommons@University of Nebraska - Lincoln. It has been accepted for inclusion in Faculty Publications, Department of Psychology by an authorized administrator of DigitalCommons@University of Nebraska - Lincoln. 


\section{Authors}

Neal Doran, Bonnie Spring, Belinda Borrelli, Dennis E. McChargue, Brian Hitsman, Raymond Niaura, and Donald Hedecker 


\title{
Elevated Positive Mood: A Mixed Blessing for Abstinence
}

\author{
Neal Doran \\ University of Illinois at Chicago
}

Belinda Borrelli

Brown Medical School and The Miriam Hospital

Brian Hitsman and Raymond Niaura

Brown Medical School and The Miriam Hospital

\author{
Bonnie Spring \\ University of Illinois at Chicago and Hines VA Hospital \\ Dennis McChargue
Illinois at Chicago and Hine \\ University of Illinois at Chicago and Hines VA Hospital
}

Donald Hedeker

University of Illinois at Chicago

\begin{abstract}
The present study, a secondary analysis of published data (B. Hitsman et al., 1999), assessed (a) the influence of initial positive mood (PM) on smoking cessation and (b) whether smokers low in PM benefited from fluoxetine versus placebo for cessation. Euthymic adult smokers $(N=103)$ received 10 weeks of cessation treatment. Analyses showed a Time $\times$ PM interaction, indicating that higher baseline PM predicted decreased abstinence during treatment but increased abstinence afterward, mediated by time to dropout. Dichotomous initial PM interacted with drug, suggesting a benefit of fluoxetine for low-PM smokers. Results indicate that lower pretreatment PM may inhibit long-term cessation. Smokers with lower baseline PM may benefit from treatment that increases PM.
\end{abstract}

Keywords: positive affect, smoking cessation, fluoxetine, SSRI

Cigarette smoking remains a major, preventable source of disease and premature death in the United States and is associated with approximately $20 \%$ of all deaths (Centers for Disease Control, 1999). Even though the negative health consequences of smoking are well established and widely known, nearly one in four American adults remains a regular smoker (Centers for Disease Control, 2002). Some evidence suggests that current smokers attempting to quit may actually be less likely to be successful than smokers of 20 years ago (Irvin \& Brandon, 2000; Irvin, Hendricks, \& Brandon, 2003). Although this hardening hypothesis is not

Neal Doran, Department of Psychology, University of Illinois at Chicago; Bonnie Spring and Dennis McChargue, Department of Psychology, University of Illinois at Chicago and Hines VA Hospital, Hines, Illinois; Belinda Borrelli, Brian Hitsman, and Raymond Niaura, Department of Psychiatry and Human Behavior, Brown Medical School and The Miriam Hospital, Providence, Rhode Island; Donald Hedeker, Division of Epidemiology and Biostatistics, School of Public Health, University of Illinois at Chicago.

This study was supported by American Heart Association Grant $0410025 Z$ to Neal Doran; a VA Merit Award to Bonnie Spring; National Heart, Lung, and Blood Institute Grant R01 62165 to Belinda Borrelli; National Institute on Drug Abuse Grant 1 K08 DA00467 to Dennis McChargue; National Cancer Institute Center Grant P50 CA84719 to Raymond Niaura and Brian Hitsman; and Mentored Clinical Scientist Development Award K08 DA017145 to Brian Hitsman. Additional funding was provided by the National Institute on Drug Abuse and the Robert Wood Johnson Foundation. Study medication was provided by the manufacturer, Eli Lilly.

Correspondence concerning this article should be addressed to Neal Doran, Department of Psychology, University of Illinois, 1007 West Harrison Street, MC 285, Chicago, IL 60607. E-mail: ndoran1@uic.edu uniformly accepted (Warner \& Burns, 2003), its expression has prompted interest in identifying psychological and/or biological conditions that impede the ability of some continuing smokers to quit successfully (Gilbert \& Gilbert, 1995; Gilbert, Gilbert, \& Schulz, 1998).

Research on psychiatric comorbidities hypothesized to inhibit smoking cessation has been focused chiefly on characteristics that are associated with negative mood. In comparison, relatively little work has examined the potential influence of positive mood on smoking behavior. Positive mood is conceptualized as a pleasant, animated mood state reflecting feelings of enthusiasm, elation, and peppiness (Watson \& Tellegen, 1985). The lack of consideration of positive mood in the tobacco literature may reflect a view that positive and negative mood are at opposite ends of a single mood construct (e.g., Russell \& Carroll, 1999), indicating that elevated positive mood is the equivalent of an absence of negative mood. However, evidence suggests that positive mood and negative mood are related but distinct constructs (Watson, Clark, \& Tellegen, 1988; Watson \& Tellegen, 1999), with different biological bases (Davidson, 1992) and psychological correlates (Watson et al., 1988).

However, the tobacco literature has recently begun to reflect greater interest in the possible impact of positive mood on smoking behavior. This research suggests that low levels of positive mood may also play an important role in maintaining smoking and inhibiting cessation. For example, in a large-scale survey study, Presson, Chassin, and Sherman (2002) found that adults with low levels of positive mood were more likely to smoke than were their counterparts with higher levels of positive mood. Cook, Spring, McChargue, and Hedeker (2004) found that anhedonic smokers (i.e., those with chronically low positive mood) reported a greater 
increase in craving during acute nicotine withdrawal than less anhedonic smokers did. Similarly, in a lab-based study, Zinser, Baker, Sherman, and Cannon (1992) found that, among continuing smokers, low levels of positive mood induced by stress predicted an increase in cigarette craving. In the same study, craving was associated with negative mood among withdrawing smokers but not among continuing smokers. Rabois and Haaga (2003) also reported that smokers who experienced decreased positive mood in response to a mood induction felt increased temptation to smoke. Further evidence relating low positive mood to urge to smoke is the finding that smokers who carry the variable number of tandem repeats polymorphism on the gene that encodes the dopamine- 4 receptor respond to smoking cues by exhibiting both disproportionately heightened cigarette cravings and diminished positive mood (Hutchison, LaChance, Niaura, Bryan, \& Smolen, 2002).

To the extent that diminished positive mood after quitting smoking predicts decreased likelihood of abstinence (al'Absi, Hatsukami, Davis, \& Wittmer, 2004), a treatment that heightens positive mood could plausibly be expected to increase the probability of abstinence. Indeed, Cook, Spring, McChargue, Borrelli, et al. (2004) found that the modestly effective cessation aid fluoxetine (Niaura et al., 2002) increased positive mood among smokers attempting to quit. Also, Shiffman et al. (2000) found that the first-line cessation treatment bupropion limited a postcessation reduction in positive mood, although a later study failed to replicate this finding (Lerman et al., 2002).

These observed links among low positive mood, prominent cigarette craving, and smoking suggest that diminished positive mood could be an important impediment to smoking cessation. However, although a low level of positive mood during nicotine withdrawal has been associated with increased craving and poor cessation outcome, to our knowledge, the impact of having a low level of positive mood prior to cessation has not been assessed. The first aim of the current study is, therefore, to test the hypothesis that smokers with lower levels of positive mood at the outset of smoking cessation treatment are less likely to quit smoking than those with higher levels of positive mood.

Additionally, because fluoxetine treatment during cessation appears to curtail post-quit decrements in positive mood (Cook, Spring, McChargue, Borrelli, et al., 2004; Shiffman et al., 2000), it seems plausible that smokers with low levels of pre-quit positive mood might especially benefit from cessation treatment incorporating fluoxetine pharmacotherapy. However, no published research has directly tested that hypothesis. The second aim of the current study is, therefore, to test the hypothesis that smokers with lower initial positive mood are more likely to quit successfully when receiving fluoxetine rather than placebo.

\section{Method}

\section{Participants}

Participants were 103 regular smokers (59\% female) who were administered mood measures as part of a placebo-controlled, double-blind trial of fluoxetine as an aid for smoking cessation plus weight control. All were between the ages of 18 and $65(M=42.1, S D=9.8)$; most were Caucasian $(99 \%)$ and college educated $(56.6 \%)$. All were enrolled in a smoking cessation plus weight gain prevention trial conducted in North Chicago (Hitsman et al., 1999), and approximately $47 \%(n=49)$ also provided data for a multisite, industry-sponsored trial of fluoxetine for smoking cessation
(Niaura et al., 2002) and comprised a portion of the samples described by Borrelli, Papandonatos, Spring, Hitsman, and Niaura (2004); Borrelli, Spring, Niaura, Hitsman, and Papandonatos (2001); Hitsman, Spring, Borrelli, Niaura, and Papandonatos (2001); and Borrelli et al. (1999). The remainder $(n=54)$ were recruited to the North Chicago site after the multisite trial had concluded.

At study entry, participants smoked an average of 28.5 cigarettes per day $(S D=10.3)$ and had a mean score of $7.0(S D=1.7)$ on the Fagerstrom Tolerance Questionnaire (FTQ; Fagerstrom, 1978). Exclusionary criteria were scores of 14 or higher on the Hamilton Depression Rating Scale (Endicott, Cohen, Nee, Fleiss, \& Sarantakos, 1981; Hamilton, 1960), pregnancy, hypertension, current use of psychotropic medication, current psychiatric illness, current use of tobacco products other than cigarettes, current use of nicotine replacement products, recent major life event, suicidal ideation, and history of bipolar disorder.

\section{Procedure}

Following initial screening, participants underwent a physical examination, medical history, chest X-ray, and blood testing (complete blood chemistry and differential). Participants were randomized on a doubleblind basis to receive 9 weeks of 30 or $60 \mathrm{mg}$ fluoxetine or placebo concurrent with 10 weekly sessions of individual, manualized cognitivebehavioral therapy for smoking cessation. Individual therapy sessions were intended to aid cessation by teaching coping skills, stimulus control techniques, and relapse prevention. Sessions lasted 60-90 min and were administered by doctoral-level therapists who participated in a standardized, prestudy training meeting. Treatment fidelity was ensured via prestudy training and a treatment manual. The treatment manual contained a checklist for each session and was completed by clinicians following each session.

At Visit 2, participants began pharmacotherapy and selected a target quit date (TQD) within the subsequent 2 weeks. The latest possible TQD was $24 \mathrm{hr}$ prior to the Week 4 visit. Participants received medication (or placebo) for approximately 2 weeks prior to the TQD. Following the 10-week treatment phase, participants attended four monthly follow-up visits, with the final visit occurring 26 weeks after the end of treatment, or 32-34 weeks post-TQD (see Niaura et al., 2002, for additional protocol details).

\section{Measures}

Smoking status. We assessed smoking status by combining three separate measures: self-reported smoking, expired air carbon monoxide (CO), and salivary cotinine, each of which we collected at the beginning of each treatment and follow-up visit. Participants who reported any smoking since the last visit, had $\mathrm{CO}$ values greater than eight parts per million, or had cotinine values greater than $20 \mathrm{ng} / \mathrm{mL}$ were classified as smokers at that visit. Smoking status was assessed over time, beginning at the fourth treatment visit (1-2 days post-TQD) through the final follow-up visit.

Positive mood. Positive mood was assessed via the Vigor subscale of the Profile of Mood States (POMS; McNair, Lorr, \& Droppleman, 1971). The Vigor subscale assesses moods such as jubilation, happiness, and peppiness, with scores ranging from 0 to 32 . Participants completed the POMS once per day for 3 consecutive days prior to beginning treatment. The average of participants' Vigor scores across these 3 days was used as a measure of baseline positive mood. The POMS Vigor subscale exhibited adequate internal consistency at baseline in the current study (Cronbach's $\alpha=.88$ ). It was chosen as the measure of positive affect in preference to alternative scales because it is the measure most frequently reported in the tobacco literature, particularly in the context of smoking cessation. The POMS Vigor subscale has been administered to measure acute effects of nicotine on positive mood and alertness (e.g., Gilbert, Dibb, Plath, \& Hiyane, 2000; Griesar, Zajdel, \& Oken, 2002; Levin et al., 1998; Spiga et 
al., 1998) as well as to measure postcessation changes in positive mood (e.g., al'Absi et al., 2004; Cook, Spring, McChargue, \& Hedeker, 2004; Jarvik et al., 2000; Patten, Martin, Calfas, Brown, \& Schroeder, 2000).

Nicotine dependence. We used the eight-item FTQ (Fagerstrom, 1978) to assess participants' degree of nicotine dependence. The FTQ consists of the sum of behavioral responses suggestive of nicotine dependence (e.g., smoking early in the morning, smoking many cigarettes per day). Scores range from 0 to 11 , with values of 7 or greater suggesting nicotine dependence.

Drug assignment. As part of the larger trial, all participants in the current study were randomized on a double-blind basis to one of three pharmacotherapy conditions: placebo $(n=34), 30 \mathrm{mg}$ fluoxetine $(n=30)$, or $60 \mathrm{mg}$ fluoxetine $(n=39)$. In the current study, all participants were coded as having received either placebo $(n=34)$ or fluoxetine $(n=69)$, after it was determined that no significant differences existed between the $30-\mathrm{mg}$ and $60 \mathrm{-mg}$ groups on a variety of variables (combined fluoxetine and norfluoxetine blood levels, nicotine dependence, baseline vigor, baseline negative affect, smoking status over time, age, gender, and post-TQD symptoms of withdrawal).

Time to dropout. Participants were considered to have dropped out of the study when they stopped attending either treatment or follow-up sessions. Time to dropout was coded as the number of weeks between the first treatment visit and the last visit attended.

\section{Analytic Plan}

The analyses tested the hypothesis that lower levels of baseline positive mood would be associated with a reduced likelihood of abstinence. The primary outcome measure was the dichotomous variable bioverified smoking status measured over the course of 10 visits (from Week 1 through 9 months post-TQD). We coded participants as abstinent (0) or smoking (1) at each visit. We performed longitudinal analysis of smoking status over the 10 time points using a logistic regression model for correlated dichotomous outcomes, estimated using the generalized estimating equations (GEE) method (Liang \& Zeger, 1986), implemented via SAS PROC GENMOD. We adopted an intent-to-treat approach. For participants with missing smoking status data, we performed no manual imputations (i.e., we treated missing as missing rather than assuming overdeterministically that missing was equal to smoking). It is important to note that GEE places no restrictions on the number of observations included per individual, so that participants with missing smoking status data were not excluded from the analysis. Instead, we estimated model parameters using all available datathe combined available smoking status data from all randomized participants.

The GEE model characterized the repeated dichotomous classifications (abstinent vs. smoking) in terms of initial cessation and time-related changes in cessation. We initially included both time and time squared terms in all analyses to assess for both linear and quadratic time trends. We included nicotine dependence, gender, and drug assignment as covariates in all analyses. Controlling for these covariates, we conducted specific tests to estimate the effect of baseline positive mood on initial smoking status and time-related changes in the effect of baseline positive mood on smoking status over time (Baseline Positive Mood $\times$ Time and Baseline Positive Mood $\times$ Time Squared interactions). We removed nonsignificant terms from the model in a backward manner (i.e., Baseline Positive Mood $\times$ Time Squared first, then Baseline Positive Mood $\times$ Time) and refit the model. The GEE model provides statistical tests that are robust to the misspecification of the dependency structure that may result from repeated assessments of individuals over time (Diggle, Liang, \& Zeger, 1994). In the current analysis, we chose an m-dependent (or Toeplitz) correlation structure on the basis of the pattern of observed correlations of smoking status over time.
Results

\section{Preliminary Analyses}

As shown in Table 1, we tested baseline demographic and smoking history variables to determine whether they were significantly associated with either baseline positive mood or drug assignment. Baseline positive mood was not associated with drug assignment, gender, age, cigarettes smoked per day, or nicotine dependence. We found no significant differences between drug groups on gender, age, cigarettes smoked per day, or nicotine dependence.

\section{Primary Analyses}

Table 2 presents the results of the GEE analysis testing the effects of baseline positive mood and time on smoking status over 10 time points (Visits 4 through 9 and four follow-up visits). We included gender, nicotine dependence, and drug assignment in the model as covariates. Nicotine dependence was the only covariate that significantly predicted smoking over time, such that participants with higher FTQ scores at baseline were more likely to continue smoking than those with lower nicotine dependence scores. Although baseline positive mood was not significantly associated with smoking status on quit day (Visit 4), there was a significant linear interaction between baseline positive mood and time $(z=-2.45, p=.014)$. To determine the direction of this interaction, we performed a median split on baseline positive mood and plotted abstinence rates of the two baseline positive mood groups (low and high) over time (see Figure 1). As the figure shows, the linear Baseline Positive Mood $\times$ Time interaction indicates that, initially, from Session 4 (the latest possible quit day) through Visit 7, participants with lower baseline positive mood were more likely to be abstinent. However, this trend reversed subsequently such that participants with lower baseline positive mood were less likely to be abstinent from Visit 8 through Visit 13 (32 weeks after quit date).

\section{Mediational Analyses}

We then conducted a series of post hoc mediational analyses to explore factors that might explain the association between baseline positive mood and smoking status over time. In testing for medi-

Table 1

Means and Standard Deviations for Baseline Smoking and Demographic Variables by Drug Assignment

\begin{tabular}{|c|c|c|c|c|c|c|}
\hline \multirow[b]{2}{*}{ Variable } & \multicolumn{2}{|c|}{$\begin{array}{l}\text { Placebo } \\
(n=34)^{\mathrm{a}}\end{array}$} & \multicolumn{2}{|c|}{$\begin{array}{l}\text { Fluoxetine } \\
(n=69)^{\mathrm{b}}\end{array}$} & \multicolumn{2}{|c|}{$\begin{array}{c}\text { All } \\
\text { participants } \\
(N=103)^{\mathrm{c}}\end{array}$} \\
\hline & $M$ & $S D$ & $M$ & $S D$ & $M$ & $S D$ \\
\hline Age (years) & 44.9 & 10.5 & 40.7 & 9.3 & 42.1 & 9.8 \\
\hline Baseline positive mood & 14.4 & 4.9 & 13.4 & 5.7 & 13.7 & 5.5 \\
\hline FTQ & 7.2 & 1.7 & 6.9 & 1.7 & 7.0 & 1.7 \\
\hline Cigarettes/day & 28.6 & 7.9 & 28.5 & 11.4 & 28.5 & 10.3 \\
\hline Weeks to dropout & 12.5 & 7.3 & 13.4 & 7.8 & 13.1 & 7.6 \\
\hline
\end{tabular}

Note. FTQ $=$ Fagerstrom Tolerance Questionnaire.

a 18 women, 16 men. ${ }^{b} 43$ women, 26 men. ${ }^{c} 61$ women, 42 men. 
Table 2

Generalized Estimating Equations Model Predicting Smoking Status Over Time

\begin{tabular}{lrll}
\hline \multicolumn{1}{c}{ Variable } & Estimate & $S E$ & $Z$ score \\
\hline Covariates & & & \\
$\quad$ Gender & -0.321 & 0.740 & -0.43 \\
$\quad$ Nicotine dependence & -0.484 & 0.180 & $-2.70^{* *}$ \\
$\quad$ Drug & -0.385 & 0.218 & -1.77 \\
Time effects & & & \\
$\quad$ Time & 0.356 & 0.064 & $5.56^{* *}$ \\
$\quad$ Time $\times$ Time & -0.009 & 0.002 & $-4.06^{* *}$ \\
Primary effects & & & \\
$\quad$ Baseline positive mood & 0.045 & 0.041 & 1.09 \\
Baseline Positive Mood $\times$ Time & -0.007 & 0.003 & $-2.45^{*}$ \\
\hline
\end{tabular}

Note. Smoking status was coded as 0 (abstinent) or 1 (smoking).

${ }^{*} p<.05 . \quad{ }^{* *} p<.01$.

ation, we used the approach recommended by Cohen and Cohen (1983). With this approach, mediation requires that a series of four steps be satisfied. First, the independent variable (IV) must significantly predict the dependent variable (DV) when the mediator is excluded from the model. Second, when the mediating variable is added to the model described in Step 1, the effect of the IV on the DV must be weakened. Third, the mediating variable must be a significant predictor of the DV when the IV is excluded from the model. Fourth, when the IV is added to the model described in Step 3, the effect of the mediator on the DV must be weakened.

We tested several variables as potential mediators explaining the changing relationship between positive mood and smoking status over time. We chose candidate variables previously shown to be predictive of smoking status, including self-efficacy (Borrelli \& Mermelstein, 1994), nicotine withdrawal symptoms (Piasecki, Jorenby, Smith, Fiore, \& Baker, 2003a, 2003b), negative mood (Kenford et al., 2002), and reasons for smoking (Schneider, 1984). We also tested changes in positive mood over time and time to dropout as potential mediators.
Analyses indicated that time to dropout was the only significant mediator of the changing association between baseline positive mood and smoking status over time. As shown in Table 2, when time to dropout was not included in the model, Baseline Positive Mood $\times$ Linear Time was a significant predictor of smoking status over time $(z=-2.45, p=.014)$. However, when time to dropout was included in the model (see Table 3 ), the Baseline Positive Mood $\times$ Linear Time term became nonsignificant $(z=-0.44$, $p=.331$ ). When Baseline Positive Mood $\times$ Linear Time was excluded from the model, time to dropout was a significant predictor of smoking status over time $(z=-5.04, p=.0001)$. Specifically, participants who dropped out earlier were more likely than others to have been smoking prior to dropping out. When Baseline Positive Mood $\times$ Linear Time was included in the model, the effect of time to dropout became nonsignificant $(z=-1.76$, $p=.079$ ). In other words, in both cases, when the second variable was added to the model, the effect of the first variable on the DV became nonsignificant, indicating that time to dropout fully mediated the association between baseline positive mood and smoking status over time. In sum, these findings indicate a significant effect of baseline positive mood on the slope representing change in smoking status over time. This effect was explained by time to dropout, which was inversely related to baseline positive mood (Pearson $r=-.21, p=.038$ ), indicating that smokers with higher levels of baseline positive mood were more likely to drop out of the study at an earlier stage.

\section{Interaction With Drug Assignment}

When we refitted the GEE model of smoking over time, including Baseline Positive Mood $\times$ Drug Assignment as a predictor, the interaction term was only a marginally significant predictor of smoking status $(z=1.55, p=.11)$. However, plots comparing those above and below the median on baseline positive mood for abstinence rates on placebo versus fluoxetine (see Figure 2) suggested an interaction that the current study was not sufficiently powered to detect. Consequently, we refitted the GEE model of smoking over time after recoding participants as either high or low

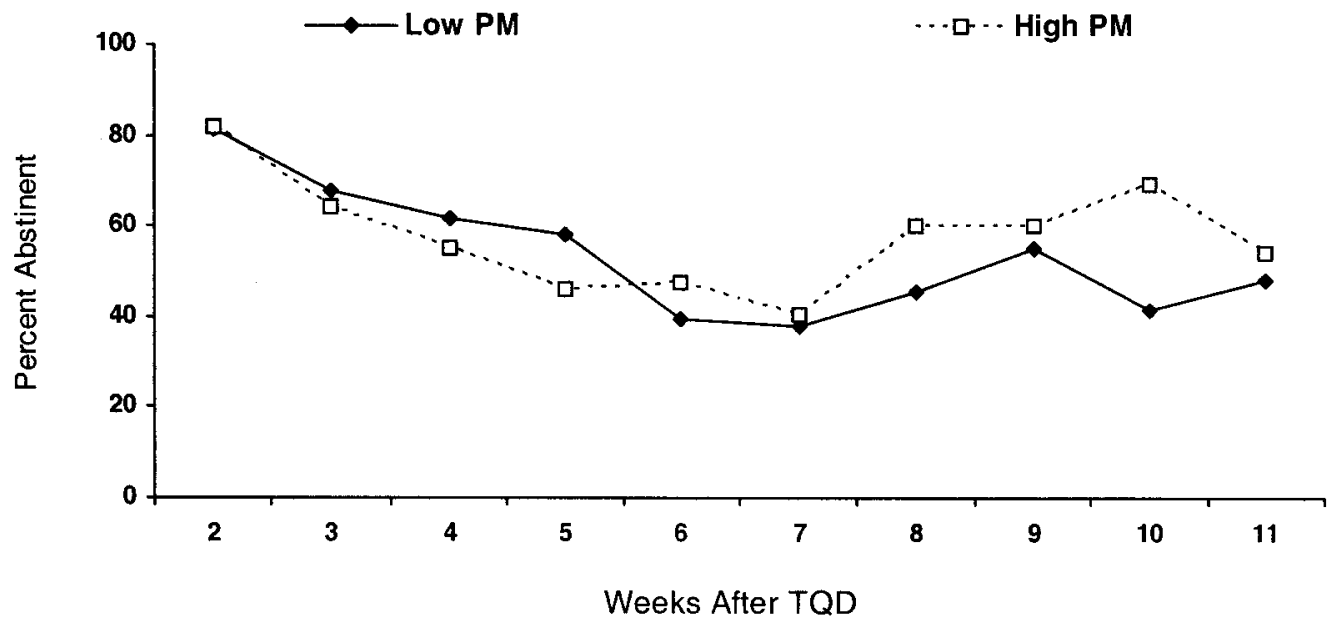

Figure 1. Percentage abstinence over time for smokers who scored above or below the median on baseline positive mood (PM; available data). $T Q D=$ target quit date. 
Table 3

Generalized Estimating Equations Mediational Model Predicting Smoking Status Over Time

\begin{tabular}{lrrr}
\hline \multicolumn{1}{c}{ Variable } & Estimate & $S E$ & $Z$ score \\
\hline Covariates & & & \\
$\quad$ Gender & -0.296 & 0.643 & -0.46 \\
$\quad$ Nicotine dependence & -0.503 & 0.179 & $-2.81^{* *}$ \\
$\quad$ Drug & -0.384 & 0.219 & -1.75 \\
Time effects & & & \\
$\quad$ Time & 0.347 & 0.064 & $5.42^{* *}$ \\
$\quad$ Time $\times$ Time & -0.008 & 0.002 & $-4.11^{* *}$ \\
$\begin{array}{l}\text { Primary effects } \\
\quad \text { Baseline positive mood }\end{array}$ & 0.024 & 0.041 & 0.59 \\
$\quad$ Baseline Positive Mood $\times$ Time & -0.001 & 0.003 & -0.44 \\
Mediator & & & \\
$\quad$ Weeks to dropout & -0.116 & 0.066 & -1.76 \\
\hline
\end{tabular}

Note. Smoking status was coded as 0 (abstinent) or 1 (smoking). $* p<.05 . \quad * * p<.01$.

in baseline positive mood on the basis of the median split. The median score for baseline positive mood in the current sample was 14. As is shown in Table 4, there was a significant interaction between drug assignment and dichotomous baseline positive mood $(z=2.31, p=.021)$.

To determine the direction of the interaction, we stratified the data on the basis of the median split of baseline positive mood and used GEE to test the effect of drug assignment for each group separately. Among the low baseline positive mood group, there was a significant effect of drug $(z=-3.32, p=.001)$, indicating that those treated with fluoxetine were more likely to be abstinent than those treated with placebo. For those with high baseline positive mood, the effect of drug was not significant $(z=0.82, p=$ 410). That is, fluoxetine had no influence on abstinence for participants who exhibited higher positive mood at study entry, but those with lower levels of baseline positive mood were significantly more likely to quit smoking on fluoxetine compared with placebo. Medication status was not associated with change in positive mood over time during treatment, $t(3,476)=-0.44, p=$ .657. Similarly, the interaction between baseline positive mood and medication status was not a significant predictor of change in positive mood over time, $t(3,476)=-1.47, p=.142$.

\section{Discussion}

The current study tests the hypothesis that low baseline positive mood negatively predicts smoking cessation in a trial of fluoxetine as an adjunct to cognitive-behavioral therapy. To our knowledge, this is the first study to directly test the influence of baseline positive mood on smoking cessation. Results show a significant effect of baseline positive mood on change in smoking status over time. At the outset of treatment, participants with higher levels of baseline positive mood showed a reduced likelihood of being abstinent. However, by the end of treatment this relationship reversed, such that throughout follow-up higher levels of baseline positive mood were associated with increased probability of abstinence. The relationship between baseline positive mood and change in smoking status over time was mediated by time to dropout, which was inversely related to baseline positive mood.
Smokers with higher levels of baseline positive mood were more likely to drop out of the study at an earlier stage, but if they did not drop out they were more likely to be abstinent at end of follow-up. We also found an interaction between dichotomous baseline positive mood and drug assignment. That is, smokers with low initial positive mood were more likely to be abstinent if treated with fluoxetine than placebo. Among those who had higher positive mood at baseline, fluoxetine had no effect on abstinence.

Surprisingly, we found that either high or low positive mood at baseline could be detrimental to cessation. Participants with heightened positive mood at baseline tended to drop out of treatment earlier than others. In the long run, though, as Figure 1 indicates, individuals with higher positive mood who remained in treatment were more successful at maintaining abstinence than participants who entered treatment with lower positive mood. We were unable to uncover an explanation for the heightened dropout of those who entered treatment with elevated baseline positive mood. For example, heightened dropout was not associated with greater nicotine dependence or withdrawal, number of previous quit attempts, medication side effects, or fluoxetine metabolite levels.

One speculative explanation for the association between baseline positive mood and time to dropout is that those with higher positive mood at baseline might have been overconfident about their ability to quit successfully. Perhaps these participants had unrealistic expectations about the easiness of quitting or about the efficacy of the medication. Subsequently, they might have felt discouraged at finding cessation difficult and therefore terminated treatment early. In a similar vein, Haaga and Stewart (1992) found that quitting smokers with moderate levels of self-efficacy for preventing a cessation lapse from becoming a relapse were more likely to be abstinent 1 year later than those with high or low self-efficacy. That is, those who were the most confident about their ability to prevent relapse did better than those with very little confidence but somewhat (nonsignificantly) less well than those with moderate confidence. In the current study we did not assess specific self-efficacy about not letting a lapse turn into a relapse. General self-efficacy was not significantly related to either baseline positive mood or time to dropout in the current study. However, general self-efficacy may be a poor proxy for more specific self-efficacy or confidence about the ability to quit smoking.

The present study is the first to suggest that smokers with low levels of pre-quit positive mood may benefit from cessation treatment that includes antidepressant pharmacotherapy. It is unclear by what mechanism fluoxetine aided cessation for smokers with low baseline positive mood. Although previous research has indicated that fluoxetine reduces post-quit decrements in positive mood (Cook, Spring, McChargue, Borrelli, et al., 2004), we found no effect of drug on change in positive mood over time. Prior findings have shown that low positive mood is associated with heightened cravings to smoke cigarettes (Cook, Spring, McChargue, \& Hedeker, 2004; Rabois \& Haaga, 2003), which could undermine successful cessation. Although an effect on craving might plausibly have explained fluoxetine's beneficial effect on abstinence for low positive affect smokers, the effect of drug on craving over time was not significant in the current study. One potential explanation for the lack of association between drug and smoking status among smokers with high baseline positive mood is that they were adversely affected by fluoxetine treatment in 


\section{Low Positive Mood}

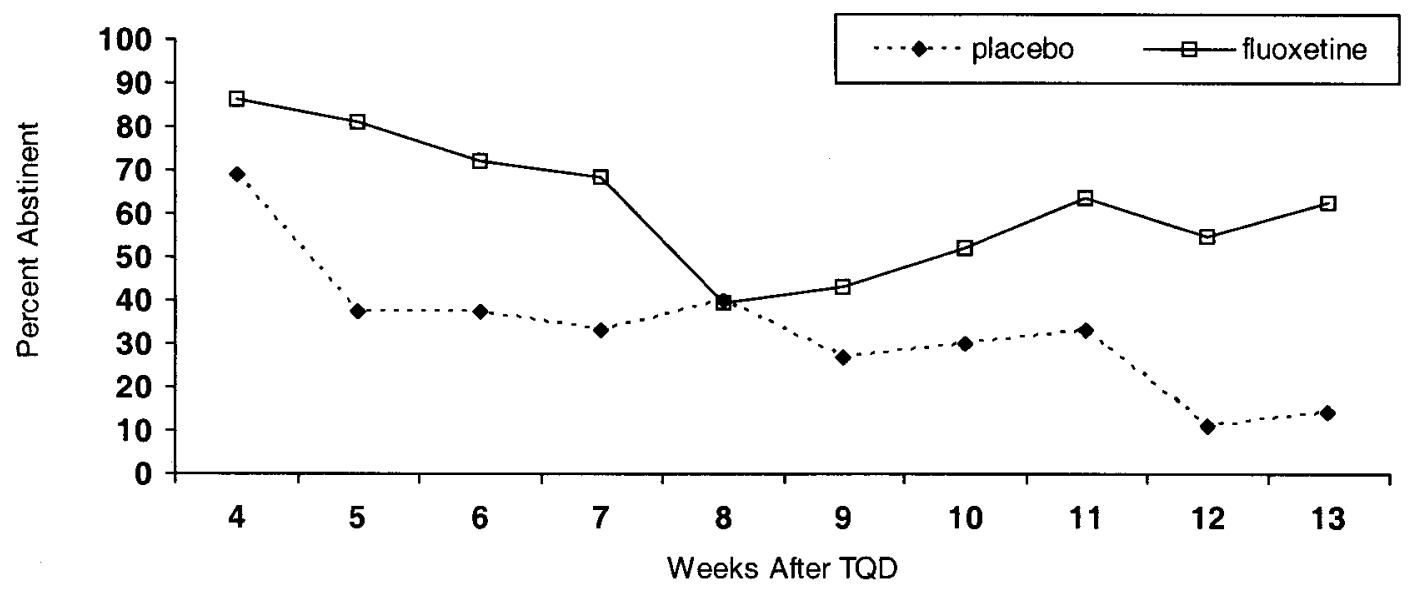

High Positive Mood

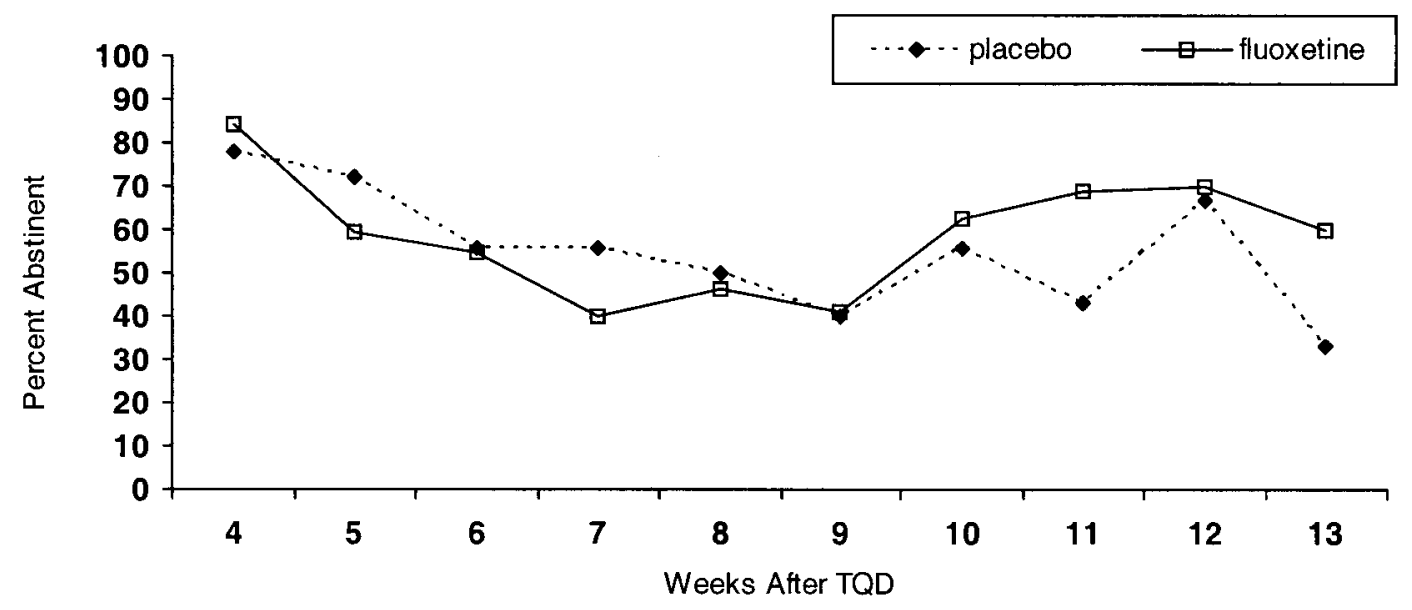

Figure 2. Percentage abstinence over time by baseline positive mood and by drug assignment. TQD = target quit date.

some way, although not in such a manner as to cause earlier dropout. Regression analyses indicated that individuals at varying levels of baseline positive mood did not drop out differentially in response to receiving drug or placebo. Alternatively, for participants with high baseline positive mood, fluoxetine may simply have had little incremental therapeutic value when added to cognitive-behavioral cessation treatment.

Generalizability of the current findings may be limited to those who share certain characteristics of the sample, such as their high motivation to quit smoking and the absence of comorbid physiological and psychiatric conditions. Also, it is unknown whether initial positive mood or fluoxetine would influence cessation in the same manner among smokers attempting to quit on their own without the assistance of a formal treatment program. Further research is needed to increase our understanding of the relationship between positive mood and smoking cessation. Researchers should explore the possibility that higher levels of positive mood are linked to increased attrition and should test potential mechanisms. Additional research is also needed to confirm or refute the present finding that smokers with low levels of positive mood derive a disproportionate cessation benefit from fluoxetine.

The current findings suggest that not only negative moods but also deficient positive moods play a role in nicotine dependence. Reports that low positive mood is linked to increased cigarette cravings during nicotine deprivation (e.g., Cook, Spring, McChargue, \& Hedeker, 2004; Rabois \& Haaga, 2003; Zinser et al., 1992) suggest that low positive mood may be implicated indirectly in cessation failure. Low positive mood during deprivation has been linked directly to cessation failure (al'Absi et al., 2004). Finally, given that low positive mood is a hallmark symptom of 
Table 4

Generalized Estimating Equations Model Predicting Smoking Status Over Time Using a Dichotomous Measure of Baseline Positive Mood

\begin{tabular}{lrrc}
\hline \multicolumn{1}{c}{ Variable } & Estimate & $S E$ & $\mathrm{Z}$ score \\
\hline Covariates & & & \\
$\quad$ Gender & -0.466 & 0.351 & -1.33 \\
$\quad$ Nicotine dependence & 0.120 & 0.105 & 1.14 \\
Time effects & & & \\
$\quad$ Time & 0.295 & 0.054 & $5.44^{* *}$ \\
$\quad$ Time $\times$ Time & -0.011 & 0.002 & $-5.03^{* *}$ \\
Primary effects & & & \\
$\quad$ Baseline positive mood & -0.769 & 0.551 & -1.40 \\
$\quad$ Drug & -1.298 & 0.460 & $-2.82^{* *}$ \\
Baseline Positive Mood $\times$ Drug & 1.565 & 0.676 & $2.31^{*}$ \\
\hline
\end{tabular}

Note. Smoking status was coded as 0 (abstinent) or 1 (smoking). ${ }^{*} p<.05 . \quad{ }^{* *} p<.01$.

depression (Clark \& Watson, 1991; Coyne, 1994) and that depressive symptoms predict cessation failure (Covey, Glassman, \& Stetner, 1990; Hughes, 1992; Kenford et al., 2002), it is not surprising that low positive mood is associated with diminished abstinence. In the current study, fluoxetine promoted abstinence among those with low baseline positive mood, although it did not prevent a reduction in positive mood after participants quit smoking.

From a clinical standpoint, these findings suggest a need for smoking cessation treatments to begin to address deficient positive mood in addition to excessive negative mood. At present, behavioral cessation treatments that include a mood management component tend to emphasize self-regulation of negative moods. It may be as important for treatments to begin to incorporate techniques that could help smokers overcome initially diminished hedonic capacity or further decrements in positive mood that occur after smoking has been discontinued.

\section{References}

al'Absi, M., Hatsukami, D., Davis, G. L., \& Wittmers, L. E. (2004). Prospective examination of effects of smoking abstinence on cortisol and withdrawal symptoms as predictors of early smoking relapse. Drug \& Alcohol Dependence, 73, 267-278.

Borrelli, B., \& Mermelstein, R. (1994). Goal setting and behavior change in a smoking cessation program. Cognitive Therapy \& Research, 18 , 69-83.

Borrelli, B., Papandonatos, G., Spring, B., Hitsman, B., \& Niaura, R. (2004). Experimenter-defined quit dates for smoking cessation: Adherence improves outcomes for women but not for men. Addiction, 99, 378-385.

Borrelli, B., Spring, B., Niaura, R., Hitsman, B., \& Papandonatos, G. (2001). Influences of gender and weight gain on short-term relapse to smoking in a cessation trial. Journal of Consulting and Clinical Psychology, 69, 511-515.

Borrelli, B., Spring, B., Niaura, R., Kristeller, J., Ockene, J. K., \& Keuthen, N. J. (1999). Weight suppression and weight rebound in ex-smokers treated with fluoxetine. Journal of Consulting and Clinical Psychology, 67, 124-131.

Centers for Disease Control. (1999). Achievements in public health, 19001999: Tobacco use--United States, 1900-1999. Morbidity \& Mortality Weekly Report, 48, 986-999.
Centers for Disease Control. (2002). Cigarette smoking among adults-United States, 2000. Morbidity \& Mortality Weekly Report, 51, 642645.

Clark, L. A., \& Watson, D. (1991). Tripartite model of anxiety and depression: Psychometric evidence and taxonomic implications. Journal of Abnormal Psychology, 100, 316-336.

Cohen, J., \& Cohen, P. (1983). Applied multiple regression/correlation analysis for the behavioral sciences (2nd ed.). Hillsdale, NJ: Erlbaum.

Cook, J. W., Spring, B., McChargue, D., Borrelli, B., Hitsman, B., Niaura, R., et al. (2004). Influence of fluoxetine on positive and negative affect in a clinic-based smoking cessation trial. Psychopharmacology, 173, 153-159.

Cook, J. W., Spring, B., McChargue, D., \& Hedeker, D. (2004). Hedonic capacity, cigarette craving, and diminished positive mood. Nicotine \& Tobacco Research, 6, 39-47.

Covey, L. S., Glassman, A. H., \& Stetner, F. (1990). Depression and depressive symptoms in smoking cessation. Comprehensive Psychiatry, $31,350-354$

Coyne, J. C. (1994). Self-reported distress: Analog or ersatz depression? Psychological Bulletin, 116, 29-45.

Davidson, R. J. (1992). Anterior asymmetry and the nature of emotion. Brain and Cognition, 20, 125-151.

Diggle, P. J., Liang, K. Y., \& Zeger, S. L. (1994). Analysis of longitudinal data. Oxford, England: Clarendon Press.

Endicott, J., Cohen, J., Nee, J., Fleiss, J., \& Sarantakos, S. (1981). Hamilton Depression Rating Scale: Extracted from regular and change versions of the Schedule for Affective Disorders and Schizophrenia. Archives of General Psychiatry, 38, 98-103.

Fagerstrom, K. O. (1978). Measuring degree of physical dependence to tobacco smoking with reference to individualization of treatment. $A d-$ dictive Behaviors, 3, 235-241.

Gilbert, D. G., Dibb, W. D., Plath, L. C., \& Hiyane, S. G. (2000). Effects of nicotine and caffeine, separately and in combination, on EEG topography, mood, heart rate, cortisol, and vigilance. Psychophysiology, 37, 583-595.

Gilbert, D. G., \& Gilbert, B. O. (1995). Personality, psychopathology, and nicotine response as mediators of the genetics of smoking. Behavior Genetics, 25, 133-147.

Gilbert, D. G., Gilbert, B. O., \& Schulz, V. L. (1998). Withdrawal symptoms: Individual differences and similarities across addictive behaviors. Personality \& Individual Differences, 24, 351-356.

Griesar, W. S., Zajdel, D. P., \& Oken, B. S. (2002). Nicotine effects on alertness and spatial attention in non-smokers. Nicotine \& Tobacco Research, 4, 185-194.

Haaga, D. A., \& Stewart, B. L. (1992). Self-efficacy for recovery from a lapse after smoking cessation. Journal of Consulting \& Clinical Psychology, 60, 24-28.

Hamilton, M. A. (1960). A rating scale for depression. Journal of Neurological and Neurosurgical Psychiatry, 23, 56-62.

Hitsman, B., Pingitore, R., Spring, B., Mahableshwarkar, A., Mizes, J. S., Seagraves, K. A., et al. (1999). Antidepressant pharmacotherapy helps some cigarette smokers more than others. Journal of Consulting and Clinical Psychology, 67, 547-554.

Hitsman, B., Spring, B., Borrelli, B., Niaura, R., \& Papandonatos, G. D. (2001). Influence of antidepressant pharmacotherapy on behavioral treatment adherence and smoking cessation outcome in a combined treatment involving fluoxetine. Experimental and Clinical Psychopharmacology, 9, 355-362.

Hughes, J. R. (1992). Tobacco withdrawal in self-quitters. Journal of Consulting and Clinical Psychology, 60, 689-697.

Hutchison, K. E., LaChance, H., Niaura, R., Bryan, A., \& Smolen, A. (2002). The DRD4 VNTR polymorphism influences reactivity to smoking cues. Journal of Abnormal Psychology, 111, 134-143. 
Irvin, J. E., \& Brandon, T. H. (2000). The increasing recalcitrance of smokers in clinical trials. Nicotine \& Tobacco Research, 2, 79-84.

Irvin, J. E., Hendricks, P. S., \& Brandon, T. H. (2003). The increasing recalcitrance of smokers in clinical trials II: Pharmacotherapy trials. Nicotine \& Tobacco Research, 5, 27-35.

Jarvik, M. E., Caskey, N. H., Wirshing, W. C., Madsen, D. C., IwamotoSchaap, P. N., Elins, J. L., et al. (2000). Bromocriptine reduces cigarette smoking. Addiction, 95, 1173-1183.

Kenford, S. L., Smith, S. S., Wetter, D. W., Jorenby, D. E., Fiore, M. C., \& Baker, T. B. (2002). Predicting relapse back to smoking: Contrasting affective and physical models of dependence. Journal of Consulting and Clinical Psychology, 70, 216-227.

Lerman, C., Roth, D., Kaufmann, V., Audrain, J., Hawk, L., Liu, A., et al. (2002). Mediating mechanisms for the impact of bupropion in smoking cessation treatment. Drug \& Alcohol Dependence, 6, 219-223.

Levin, E. D., Conners, C. K., Silva, D., Hinton, S. C., Meck, W. H., March, J., \& Rose, J. E. (1998). Transdermal nicotine effects on attention. Psychopharmacology, 140, 135-141.

Liang, K. Y., \& Zeger, S. L. (1986). Longitudinal data analysis using generalized linear models. Biometrika, 73, 13-22.

McNair, D. M., Lorr, M., \& Droppleman, L. F. (1971). Profile of Mood States manual. San Diego, CA: Educational and Industrial Testing Service.

Niaura, R., Spring, B., Borrelli, B., Hedeker, D., Goldstein, M. G., Keuthen, N., et al. (2002). Multicenter trial of fluoxetine as an adjunct to behavioral smoking cessation treatment. Journal of Consulting and Clinical Psychology, 70, 887-896.

Patten, C. A., Martin, J. E., Calfas, K. J., Brown, S. A., \& Schroeder, D. R. (2000). Brief report effect of three smoking cessation treatments on nicotine withdrawal in 141 abstinent alcoholic smokers. Addictive Behaviors, 25, 301-306.

Piasecki, T. M., Jorenby, D. E., Smith, S. S., Fiore, M. C., \& Baker, T. B. (2003a). Smoking withdrawal dynamics: II. Improved tests of withdrawal-relapse relations. Journal of Abnormal Psychology, 112, $14-27$.

Piasecki, T. M., Jorenby, D. E., Smith, S. S., Fiore, M. C., \& Baker, T. B. (2003b). Smoking withdrawal dynamics: III. Correlates of withdrawal heterogeneity. Experimental and Clinical Psychopharmacology, 11, 276-285.

Presson, C., Chassin, L., \& Sherman, S. J. (2002). Psychosocial antecedents of tobacco chipping. Health Psychology, 21, 384-392.

Rabois, D., \& Haaga, D. A. F. (2003). The influence of cognitive coping and mood on smokers' self-efficacy and temptation. Addictive Behaviors, 28, 561-573.

Russell, J. A., \& Carroll, J. M. (1999). On the bipolarity of positive and negative affect. Psychological Bulletin, 125, 3-30.

Schneider, S. (1984). Who quits smoking in a behavioral treatment program? Addictive Behaviors, 9, 373-381.

Shiffman, S., Johnston, J. A., Khayrallah, M., Elash, C. A., Gwaltney, C. J., Paty, J. A., et al. (2000). The effect of bupropion on nicotine craving and withdrawal. Psychopharmacology, 148, 33-40.

Spiga, R., Day, J. D., Schmitz, J. M., Broitman, M., Elk, R., \& CapertonBrown, H. (1998). Context modulated effects of nicotine abstinence on human cooperative responding. Experimental and Clinical Psychopharmacology, 6, 390-398.

Warner, K. E., \& Burns, D. M. (2003). Hardening and the hard-core smoker: Concepts, evidence, and implications. Nicotine \& Tobacco Research, 5, 37-48.

Watson, D., Clark, L. A., \& Tellegen, A. (1988). Development and validation of brief measures of positive and negative affect: The PANAS scales. Journal of Personality and Social Psychology, 54, 1063-1070.

Watson, D., \& Tellegen, A. (1985). Toward a consensual structurc of mood. Psychological Bulletin, 98, 219-235.

Watson, D., \& Tellegen, A. (1999). Issues in the dimensional structure of affect-Effects of descriptors, measurement error, and response formats: Comment on Russell and Carroll (1999). Psychological Bulletin, I25, 601-610.

Zinser, M. C., Baker, T. B., Sherman, J. E., \& Cannon, D. S. (1992). Relation between self-reported affect and drug urges and cravings in continuing and withdrawing smokers. Journal of Abnormal Psychology, 101, 617-629.

Received September 20, 2004

Revision received February 1, 2005 Accepted February 4, 2005 